\title{
Modelling a reef as an extended sound source increases the predicted range at which reef noise may be heard by fish larvae
}

\author{
Craig A. Radford ${ }^{1, *}$, Christopher T. Tindle ${ }^{2}$, John C. Montgomery ${ }^{1}$, Andrew G. Jeffs ${ }^{1}$ \\ ${ }^{1}$ Leigh Marine Laboratory, University of Auckland, PO Box 349, Warkworth 0941, New Zealand \\ ${ }^{2}$ Department of Physics, University of Auckland, Private Bag 92019, Auckland 1142, New Zealand
}

\begin{abstract}
Underwater sound emanating from reefs has been shown to be attractive to pre-settlement larval stages of fish and crustaceans, but its ecological importance depends on the range at which this cue can be detected by these larvae. Here we show, through field measurement and modelling, that the spatially extended sound source of a reef creates a surrounding zone, which extends for a distance offshore equal to the length of the reef, within which there is almost no loss in the sound level. Beyond this zone, the sound level decreases with cylindrical spreading plus any seafloor attenuation. This 'reef effect' means that the sound from a reef would be detectable at a much greater distance from the reef than would be estimated from a spot measurement near the reef or by using theoretical models of sound spreading from a point source. The greater reach for sound emanating from a reef means that reef noise could play a greater role in directing larval reef fishes and crabs to suitable settlement habitats than previously estimated.
\end{abstract}

KEY WORDS: Larval fish - Ambient underwater sound · Orientation cue - Acoustic cue · Reef sound $\cdot$ Settlement habitats

Resale or republication not permitted without written consent of the publisher

\section{INTRODUCTION}

The early life history of many coastal reef fishes and crustaceans, such as lobsters and crabs, are characterised by larval stages which are frequently dispersed tens to hundreds of kilometres offshore by water currents (Moser et al. 1984, Leis 1991, Atema et al. 2002). For these larvae, returning to coastal waters in order to settle back into suitable reef habitats is a significant challenge. Recent research has shown that pre-settlement larvae of fish and crabs have remarkable sensory (Atema et al. 2002, Myrberg \& Fuiman 2002, Lecchini et al. 2005a,b) and swimming (Leis 1991, 2006, Shanks 1995, Stobutzki \& Bellwood 1997, Stobutzki 1998, Fisher \& Bellwood 2001, Fisher et al. 2005) abilities that aid their directed movement toward suitable settlement reef habitats. In particular, field studies have identified ambient underwater reef noise as an orientation and settlement cue for the larvae of a wide range of temperate and tropical reef fish (Tolimieri et al. 2000, 2004, Leis \& Carson-Ewart 2003, Simpson et al. 2004, 2005, 2008, Leis \& Lockett 2005), and crab larval stages (Jeffs et al. 2003, Radford et al. 2007; Stanley et al. 2010).

Sound can complement other options, such as responding to visual and chemical cues, because it is transmitted over relatively long distances in water (e.g. in a free field situation a $500 \mathrm{~Hz}$ sound only suffers $1 \mathrm{~dB}$ of attenuation in $100 \mathrm{~km}$ of propagation in seawater), and radiates out in all directions from a reef. Underwater sound is also capable of carrying information on both habitat direction and quality (Hawkins \& Myrberg 1983, Rogers \& Cox 1988, Kingsford et al. 2002, Montgomery et al. 2006, Radford et al. 2010). However, the potential importance of sound in relation to other cues will depend on the effective range of reef sound, which in turn depends 
on the nature of the source, the characteristics of sound transmission in the underwater environment, and the hearing abilities of the larvae.

Previous studies estimating the distances that larval fish could potentially detect coastal reef noise provide estimates ranging from $500 \mathrm{~m}$ to $\sim 5 \mathrm{~km}$ (Egner \& Mann 2005, Mann et al. 2007, Wright et al. 2008, 2010). In particular, Egner \& Mann (2005) calculated that the damselfish Abudefduf saxatilis would not be able to detect a reef beyond $0.54 \mathrm{~km}$, while Mann et al. (2007) calculated that sleeper goby Dormitator latifrons would not be able to detect a reef that was $>1 \mathrm{~km}$ away. Using hearing thresholds for pre-settlement coral trout Plectropomus leopardus, Wright et al. (2008) calculated that these fish could detect a 300 to $400 \mathrm{~Hz}$ reef sound signal at $4.3 \mathrm{~km}$ offshore. However, all of these studies have assumed that the loss of reef noise travelling through shallow coastal waters can be reliably estimated by using simplistic theoretical models of either spherical or cylindrical spreading from a point sound source. Consequently, previous researchers have recognised the need for actual measurements of sound fields at different distances from reefs (Mann et al. 2007). The aim of this study was to examine the sound field of an isolated shallow water reef using both experimental measurements and a theoretical model.

\section{MATERIALS AND METHODS}

\section{Reef propagation experiment}

An experiment was undertaken at the south-eastern tip of Taranga Island, north-eastern New Zealand $\left(35^{\circ} 58^{\prime} \mathrm{S}, 174^{\circ} 45^{\prime} \mathrm{E}\right)$. This is an isolated rocky islet and the next available source of reef sound was $\sim 30 \mathrm{~km}$ away, so there were no competing sources of reef sound. The particular reef of interest was $\sim 600 \mathrm{~m}$ long with a near vertical reef face dropping down to around $40 \mathrm{~m}$ depth. Ambient underwater sound was recorded at dusk to capture the 'dusk chorus' generated by the feeding activity of the sea urchin Evechinus chloroticus that is found residing only on rocky reefs (Radford et al. 2008a,b). The only other known soniferous species dwelling in this habitat are snapping shrimp. These animals produce sound in the 3 to $22 \mathrm{kHz}$ range, with the most intense sound being around 7 to $11 \mathrm{kHz}$, which is well beyond the dominant sound frequency range emanating from rocky reefs and examined in this study (Radford et al. 2008a,b). Sound was recorded at $15 \mathrm{~m}$ water depth using 2 acoustic recording stations, a reference station moored $200 \mathrm{~m}$ off the reef edge and a movable station which was positioned to record at various distances from the reef edge $(200,500,1000$, 2000 and $5000 \mathrm{~m}$ ). The water depth increased slowly from 55 to $70 \mathrm{~m}$ over the same distance offshore of the reef, and the seafloor within this area was largely homogenous, consisting of fine sandy mud. The reference station recorded continuously for the duration of the experiment; the movable station recorded for $5 \mathrm{~min}$ at each distance. Both the reference hydrophone and movable hydrophone systems consisted of a calibrated SQ03 wideband omnidirectional hydrophone (Sensor Technology), with a flat frequency response curve from $10 \mathrm{~Hz}$ to $60 \mathrm{kHz}$ and a digital recorder (SD722, Sound Devices).

Each simultaneous 5 min recording was inspected using Adobe Audition, and any sections with transient anthropogenic sources (e.g. the sound of waves slapping against the hydrophone barrel and distant vessel engines) were removed, leaving at least $3.5 \mathrm{~min}$ of recording for each site. The recorded sound data were band-pass filtered between 100 and $5000 \mathrm{~Hz}$ to include the broad peak between 500 and $2000 \mathrm{~Hz}$ generated by the feeding activity of the sea urchin Evechinus chloroticus. Power levels (dB re $1 \mu \mathrm{Pa}$ ) in the 100 to $2500 \mathrm{~Hz}$ band were found using fast Fourier transform analyses of 6 randomly selected $30 \mathrm{~s}$ sound samples. By having a reference hydrophone recording at $200 \mathrm{~m}$ off the reef edge while the second hydrophone was moved to various distances from the reef edge, as described above, the sound level could be normalised for the change in source level during the length of the experiment. The drop in sound level (root mean square) in the 100 to $2500 \mathrm{~Hz}$ band width due to attenuation could then be calculated by analysing $6 \times 30 \mathrm{~s}$ (180 s of total recording time) of cleaned data, recorded during the same period by the reference hydrophone and the movable hydrophone. The resulting sound level as a function of distance was compared to the traditional cylindrical sound propagation model (Mann 2006).

\section{Extended reef model}

The effect of a finite reef size on the sound level as a function of range can be assessed using a simple model. The model is introduced because it approximates the typical coastal situation of an extended reef adjacent to shallow water which forms an acoustic wave guide. In most cases there will be a critical angle such that sound propagation at grazing angles less than the critical angle will be totally 
reflected at the sea surface and seafloor. The sound energy is therefore trapped in the water layer and the intensity would decrease with cylindrical spreading if the sound source had small spatial extent, i.e. approximated to a point source. The model enables estimation of the distance from the reef at which cylindrical spreading begins and beyond which the reef can be considered a point source.

We consider shallow water of constant depth $H$ with perfectly reflecting sea surface and seafloor. We also assume that the reef can be approximated by a vertical plane of length $2 a$ and height $H$ covered with omnidirectional point sources. If $Q$ is the total acoustic power output of the reef, the intensity $I$ at a perpendicular distance $D$ from the centre of the reef is given by (see Appendix 1 for derivation):

$$
I=\left(\frac{Q}{\pi a H}\right) \ln \left[\frac{a}{D}\left(1+\frac{a^{2}}{D^{2}}\right)^{1 / 2}\right]
$$

Use of this formula shows that near the reef there is a 'reef effect' in which the resulting sound field falls off slowly with distance.

At large distances $D \gg 2 a$ the intensity is approximated by:

$$
I \approx\left(\frac{Q}{\pi H D}\right)
$$

which corresponds to cylindrical spreading. Thus the model predicts the existence of a 'reef effect' that extends for a distance offshore approximately equal to the length of the reef.

\section{RESULTS}

\section{Reef propagation experiment}

In spectra recorded at the 5 stations (i.e. 200, 500, 1000,2000 and $5000 \mathrm{~m}$ ) there was a broad peak from 500 to $2500 \mathrm{~Hz}$ centred at $\sim 1400 \mathrm{~Hz}$. This was the dusk chorus generated by sea urchins feeding on the reef (Fig. 1). At a distance $200 \mathrm{~m}$ from the reef the hydrophones were side by side and produced almost identical spectra (Fig. 1a,f). When the movable hydrophone was at $500 \mathrm{~m}$, the sound level in the $100 \mathrm{~Hz}$ to $5 \mathrm{kHz}$ band was the same as that recorded by the reference hydrophone at $200 \mathrm{~m}$ (Fig. 1b), indicating that there is a zone surrounding the reef where the sound level decreases very slowly with distance. When the movable hydrophone was at 1,2 and $5 \mathrm{~km}$ (Fig. 1c-e) there was a steady decrease in sound energy with distance in the $100 \mathrm{~Hz}$ to $2.5 \mathrm{kHz}$ band. At $5 \mathrm{~km}$ there was a $12.2 \mathrm{~dB}$ re $1 \mu^{2} \mathrm{~Pa}^{2} \mathrm{~Hz}^{-1}$ difference at the spectral peak $(1400 \mathrm{~Hz})$.

Simultaneous recording at the reference hydrophone and movable hydrophone allowed for the extraction of range dependence by normalising the measurements to a constant source level (Table 1) and as a function of distance from the reef (Fig. 2). The level differences between reference and movable hydrophones were then used to determine the sound level relative to the level of $106 \mathrm{~dB}$ determined at $500 \mathrm{~m}$. The sound level at $200 \mathrm{~m}$ was almost the same as that at $500 \mathrm{~m}$ and illustrates the 'reef effect' predicted by our theoretical model for an extended reef of this length.

The reef effect becomes clear when the experimentally measured sound levels were plotted as a function of distance from the reef and compared with theoretical values calculated for cylindrical spreading from a point source of an equivalent level (Fig. 2). Both theoretical curves fitted to the data were adjusted to account for seafloor attenuation which had previously been measured at $0.4 \mathrm{~dB} \mathrm{~km}^{-1}$ in this area (C. Tindle unpubl. data). Accounting for this attenuation improved the fit of the theoretical extended reef model (Eq. 1), especially for the range $500 \mathrm{~m}$ to $5 \mathrm{~km}$. The sea conditions during the experimental sampling were flat calm and therefore it is highly unlikely there was any other attenuation, such as due to surface waves. Both the extended reef model and cylindrical spreading provide a good fit to the data from $500 \mathrm{~m}$ to $5 \mathrm{~km}$ (Fig. 2), but only the extended reef model provides a reasonable fit through to the $200 \mathrm{~m}$ data point (Fig. 2, solid curve). Ideally, it would have been good to have more experimental data points within the range. However, field sampling was limited by the time and equipment available, as well as the rare occurrence of being able to sample at dusk with very calm sea conditions at a highly exposed offshore location.

At a distance off the reef of $200 \mathrm{~m}$ the plotted curve for the extended reef model is $6 \mathrm{~dB}$ lower than for cylindrical spreading (Fig. 2). If the source level was defined as the equivalent sound level $1 \mathrm{~m}$ from a spherically symmetric source then extrapolation back to $1 \mathrm{~m}$ shows that cylindrical spreading corresponds to a point source level of $132 \mathrm{~dB}$ whereas for the extended reef model it is only $114 \mathrm{~dB}$, giving a difference of $18 \mathrm{~dB}$. The notion of measuring the sound level a short defined distance from a real reef with uneven topography is somewhat artificial, but it is clear that the sound level near an extended reef was significantly lower than the level near a hypothetical point reef producing the equivalent sound field at greater distances away. 

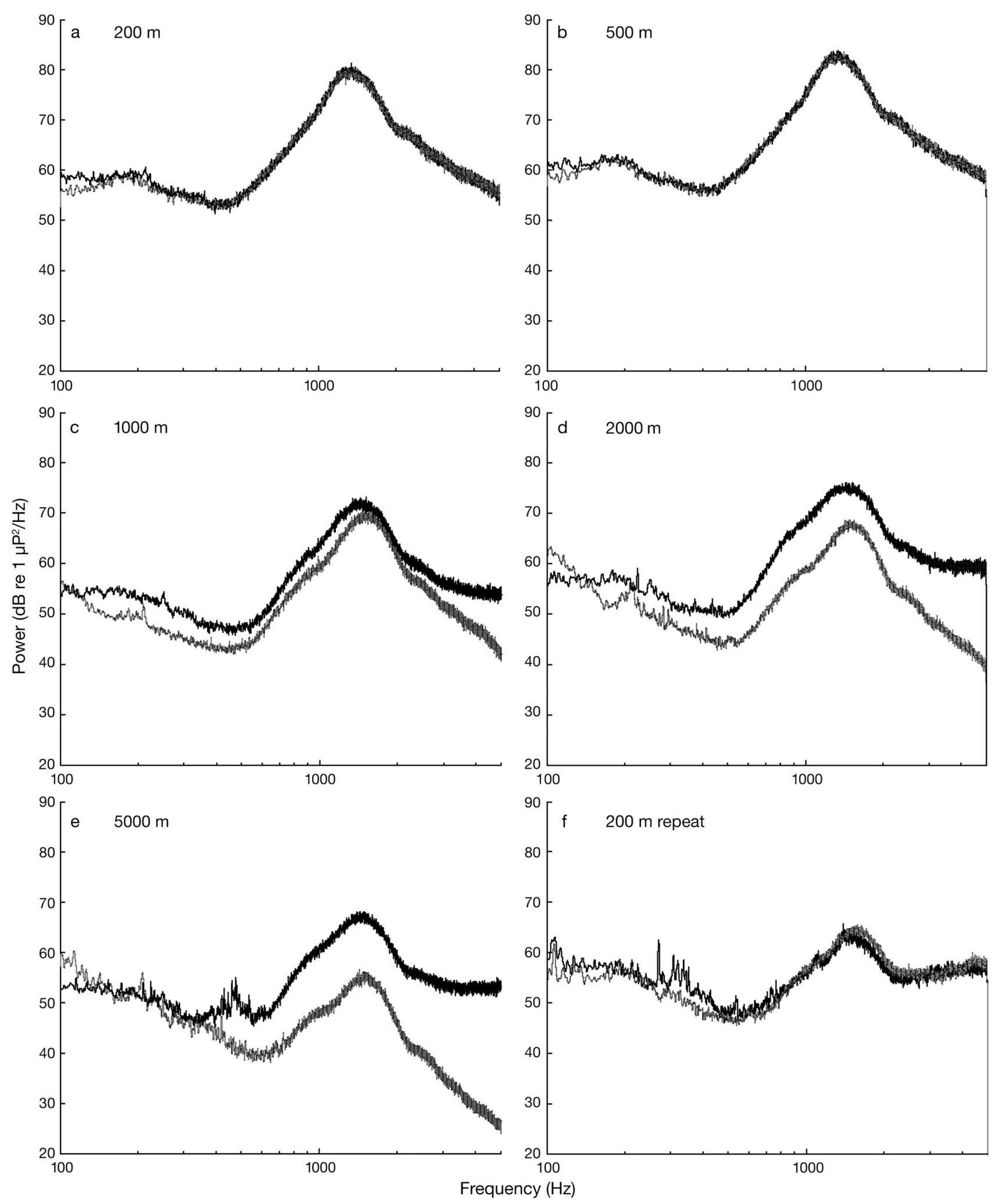

Fig. 1. Power spectra from south-eastern reef of Taranga Island, New Zealand, showing the dusk chorus of the sea urchin Evechinus chloroticus recorded by a movable hydrophone (grey line) and by a reference hydrophone (black line) located at $200 \mathrm{~m}$ from the reef. The lines are mostly superimposed when the movable hydrophone is located at 200 and $500 \mathrm{~m}$ from the reef. Times of measurements are given in Table 1 
Table 1. Sound pressure level (SPL; dB re $1 \mu \mathrm{Pa}$ ) in the frequency band of 100 to $2500 \mathrm{~Hz}$ as a function of distance from the south-eastern reef of Taranga Island at dusk, recorded by a movable hydrophone $(\mathrm{MH})$ and compared to a reference hydrophone (RH) located at a distance of $200 \mathrm{~m}$ from the reef

\begin{tabular}{|lcrrr|}
\hline \multirow{2}{*}{$\begin{array}{l}\text { Distance } \\
\text { from reef } \\
\text { to } \mathrm{MH}(\mathrm{km})\end{array}$} & $\begin{array}{c}\text { Time of } \\
\text { recording } \\
(\mathrm{h})\end{array}$ & $\mathrm{RH}$ & $\begin{array}{c}\text { MH } \\
(\mathrm{dB} \text { re } 1 \mu \mathrm{Pa})\end{array}$ & $\begin{array}{c}\text { Difference between } \\
\mathrm{RH} \& \mathrm{MH}\end{array}$ \\
\cline { 3 - 5 } 0.2 & $21: 20$ & 109.9 & 110.0 & 0.1 \\
0.5 & $21: 41$ & 105.9 & 106.1 & 0.2 \\
1 & $22: 06$ & 102.9 & 100.0 & 2.9 \\
2 & $22: 16$ & 103.5 & 96.4 & 7.1 \\
5 & $22: 30$ & 98.4 & 85.5 & 12.9 \\
0.2 & $22: 46$ & 93.8 & 93.5 & 0.3 \\
\hline
\end{tabular}

\section{Extended reef model}

For comparison, 2-dimensional views of the sound fields generated by our extended reef model and the traditional cylindrical spreading model from a point source were prepared based on a nominal sound level of $140 \mathrm{~dB}$ at a distance $20 \mathrm{~m}$ from the reef (Fig. 3). Comparison between the 2 views shows that the sound level at a distance $>500 \mathrm{~m}$ from the extended reef is $\sim 6 \mathrm{~dB}$ greater than for the point source. Secondly, the 'reef effect' clearly creates a zone near the reef in which the sound field changes very slowly with distance from the reef. However, for the extended reef model, as distance from the reef

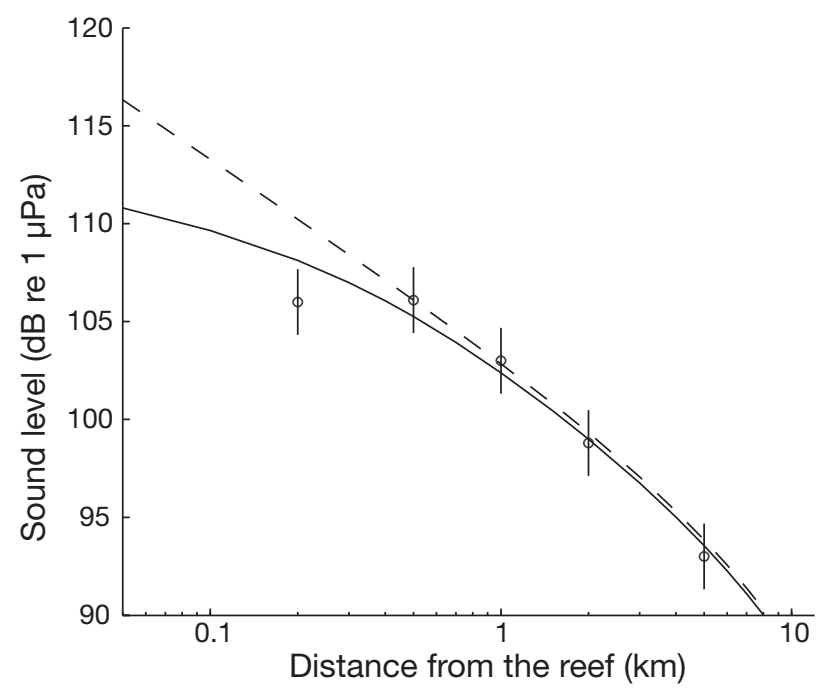

Fig. 2. Sound level as a function of distance from the reef. Results of field measurements (means $\pm 1 \mathrm{SD}$ ) conducted separately (C. Tindle unpubl. data). The solid curve is the best fit using our extended reef model, while the dashed curve is the best fit assuming cylindrical spreading. Based on the field measurements, both curves incorporate $0.4 \mathrm{~dB}$ $\mathrm{km}^{-1}$ (C. Tindle unpubl. data) of attenuation due to the fine sandy mud seafloor increases the dispersal of the reef sound increasingly conforms to cylindrical spreading. At distances greater than the length of the reef the noise from the reef can be approximated as a point source.

\section{DISCUSSION}

Our field measurements of the attenuation of noise from an isolated $600 \mathrm{~m}$ long reef at increasing distances from the centre of the reef are inconsistent with calculations based only on the assumption of spherical or cylindrical spreading to estimate the far field intensity of reef sound (Figs. 1, $2,3)$. Field measurements clearly showed a zone surrounding the reef where there is little loss of sound which we have called the 'reef effect', as predicted by our extended reef model. These field measurements also showed that at distances greater than the length of the reef, or where the receiver subtends an angle of $90^{\circ}$ from the reef, sound energy decreases due to cylindrical spreading, plus any seafloor attenuation. However, our results show that a spot measurement of sound level near a reef must be used with caution to predict the sound level far from the

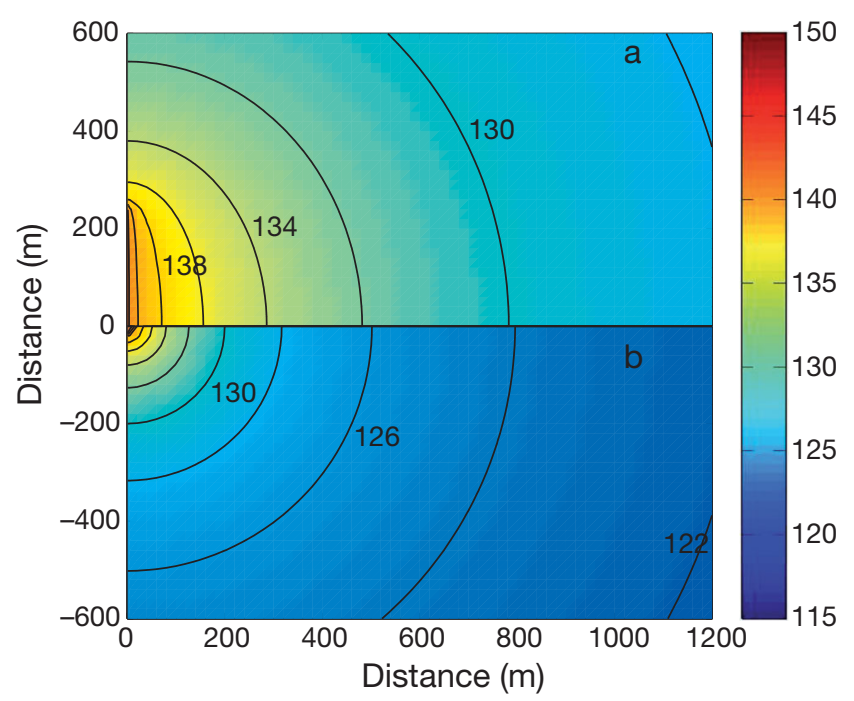

Fig. 3. Sound level contours generated by the extended reef model, for a theoretical reef of length $500 \mathrm{~m} \mathrm{(a),} \mathrm{and} \mathrm{by} \mathrm{the}$ traditional model of cylindrical spreading from a point source (b). The sound level at $20 \mathrm{~m}$ from the origin is $140 \mathrm{~dB}$ for both sound fields, representing a typical field measurement. However, the far field is quite different in the 2 cases: sound from the extended reef model does not conform to cylindrical spreading until beyond the 'reef effect' zone which extends $\sim 500 \mathrm{~m}$ from the centre of the reef 
reef. A cylindrical spreading model will only produce reliable results if based on a spot measurement of the ambient sound level made at a distance greater or equal to the length of the reef.

To assess the implication of these results, we combined our more appropriate model of extended reef noise spreading with previous measurements of the acoustic sensory thresholds of larval fish (Wright et al. 2010) in order to estimate the distances offshore that a larva would be capable of detecting our $600 \mathrm{~m}$ reef (Fig. 4). Of 5 reef fish species for which the larva have been previously examined for hearing thresholds, the Spanish flag snapper Lutjanus carponotatus had the greatest overall acoustic sensitivity and was most sensitive to sound at $100 \mathrm{~Hz}$ (Fig. 4, solid line) (Wright et al. 2010). The least acoustically sensitive larva of the reef fish species examined was the Ambon damselfish Pomacentrus amboinensis, which showed highest acoustic sensitivity at $400 \mathrm{~Hz}$ (Fig. 4, dashed line) (Wright et al. 2010). The measured acoustic sensitivity of these 2 species were compared

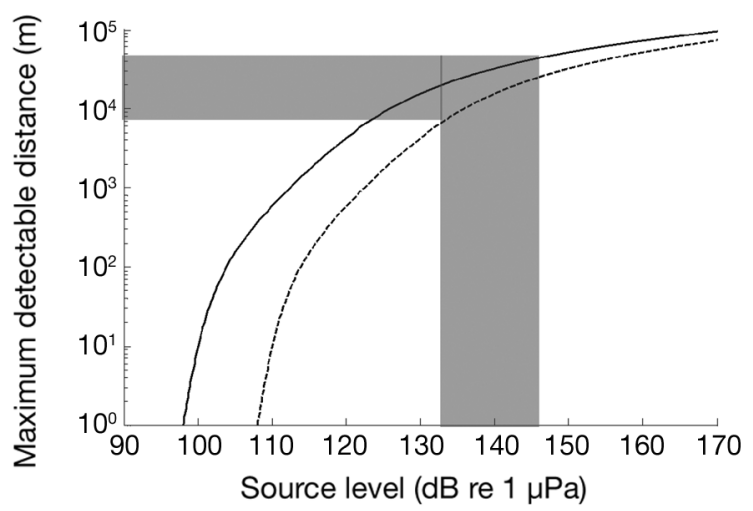

Fig. 4. Estimated maximum distance of sound detection as a function of source level, calculated from our extended reef model, for larvae of 2 fish species. Curves are anchored on the $x$-axis by the hearing threshold levels reported by Wright et al. (2010). Solid curve = Lutjanus carponatus, whose larva had the lowest hearing threshold (98 dB re $1 \mathrm{uPa} @ 100 \mathrm{~Hz}$ ) among the species studied. Dashed curve= Pomacentrus ambionensis, the species with the least sensitive hearing and highest hearing threshold (108 dB re $1 \mu \mathrm{Pa})$. The calculated range of sound detection for each species can be obtained by reading off the distance from the $y$-axis. For example, for $P$. ambionensis a source level of $134 \mathrm{~dB}$ gives a calculated range of $\sim 8 \mathrm{~km}$. The shaded area represents the range between the dusk chorus levels measured from a tropical reef at Lizard Island, Great Barrier Reef, Australia (109 dB re $1 \mu \mathrm{Pa} @ 400 \mathrm{~Hz}$; C. Radford unpubl.) and from a temperate reef in New Zealand (145 dB re $1 \mu \mathrm{Pa}$; Radford et al. 2008a). The intersection of this area with the $y$-axis represents the range of maximum distances that fish larvae studied by Wright et al. (2010) could detect reef sound, taking account of the 'reef effect' in the proposed extended reef model against the measured sound levels of temperate and tropical reefs on a new moon during dusk: $145 \mathrm{~dB}$ re $1 \mu \mathrm{Pa}$ (Radford et al. 2008a) and $134 \mathrm{~dB}$ re $1 \mu \mathrm{Pa}(\mathrm{C}$. Radford unpubl.), respectively (Fig. 4, shaded vertical rectangle). This analysis indicates that the damselfish larva could be expected to be able to begin to detect the tropical reef within a range of $8 \mathrm{~km}$, while the Spanish flag snapper larva could detect the temperate reef within a range of $50 \mathrm{~km}$. These ranges are significantly in excess of previous estimates for the distance over which larval fish could be capable of detecting reef noise (Egner \& Mann 2005, Wright et al. 2008, 2010).

It has been widely accepted that fish are likely to respond to both the pressure and particle motion components of underwater sound, with the latter being more important for the majority of fish species (Popper \& Fay 2011). To date there is only been one study that has measured the hearing sensitivity of a marine species of fish to particle motion using electrophysiological methods (Wysocki et al. 2009), showing that the tropical damselfish Chromis chromis was sensitive to particle motion (adjusted for critical bandwidth) of $7.59 \times 10^{-10} \mathrm{~m}$ at $200 \mathrm{~Hz}$. Measurements of particle motion were not possible in the present study due to security restrictions preventing access to appropriate detection equipment. However, because our recordings were conducted in the farfield, sound pressure will be directly related to particle motion by $p=\rho c v$ and $v=\omega A$, where $p=$ pressure, $\rho=$ density of seawater, $c=$ speed of sound, $v=$ particle velocity, $\omega=$ angular acceleration and $A=$ particle displacement. Therefore, for a sound level of $134 \mathrm{~dB}$ re $1 \mu \mathrm{Pa}$, which was recorded at Lizard Island during dusk, the particle displacement generated at $200 \mathrm{~Hz}$ would be $2.65 \times 10^{-9} \mathrm{~m}$, indicating that the sound intensities produced by this reef could be detected by these tropical damselfish. Assuming that pre-settlement larvae of $C$. chromis had the same hearing threshold as adults (Wysocki et al. 2009), the proposed model indicates that this species could detect the reef from $\sim 20 \mathrm{~km}$ away by sensing only particle motion.

The present study has shown that there is a zone surrounding the reef where the sound level decreases slowly with distance. If a pre-settlement fish was only detecting sound pressure it would be very difficult for the fish to determine sound direction. However, fish are capable of detecting both pressure and particle motions (Popper \& Fay 2011). Particle motion is a vector quantity and can provide the presettlement fish with some information regarding the directional source of the sound. In future studies it 
would be useful to have direct measurements of the particle motion component of the acoustic field to provide direct information on the directionality of the signal within the 'reef effect' zone.

In conclusion, the greater distances offshore that reef noise travels may enhance its importance in settlement and habitat selection in this critical life history phase of fish and invertebrates. Furthermore, there is emerging evidence that reef noise also plays a much wider ecological role in the spatial orientation behaviour of a very wide range of organisms, including many pelagic organisms, as well as larval, juvenile and adult reef organisms (Simpson et al. 2007, 2011, Stanley et al. 2010, Radford et al. 2011). This highlights the importance of understanding the influence of sound for the replenishment of coastal fisheries and maintaining contiguous stretches of healthy reefs. Furthermore, it indicates the need to manage the underwater acoustic environment with respect to rising levels of anthropogenic noise.

Acknowledgements. This work was made possible by support from the Marsden Fund administered by the Royal Society of New Zealand to Craig Radford, and support from the Glenn Family Foundation to Andrew Jeffs. Thank you to our acoustics laboratory group and especially 3 anonymous reviewers for input that greatly improved our manuscript.

\section{LITERATURE CITED}

Atema J, Kingsford MJ, Gerlach G (2002) Larval fish could use odour for detection, retention and orientation to reefs. Mar Ecol Prog Ser 241:151-160

Egner SA, Mann DA (2005) Auditory sensitivity of the sergeant major damselfish Abudeduf saxitalis from postsettlement juvenile to adult. Mar Ecol Prog Ser 285: 213-222

Fisher R, Bellwood DR (2001) Effects of feeding on the sustained swimming abilities of late-stage larval Amphiprion melanopus. Coral Reefs 20:151-154

Fisher R, Leis JM, Clarke DL, Wilson SK (2005) Critical swimming speeds of late stage coral reef fish larvae: variation within species, among species and between species. Mar Biol 148:1425-1434

Hawkins AD, Myrberg AA (1983) Hearing and sound communication underwater. In: Lewis B (ed) Bioacoustics: a comparative approach. Academic Press, New York, NY, p 347-405

> Jeffs A, Tolimieri N, Montgomery JC (2003) Crabs on cue for the coast: the use of underwater sound for orientation by pelagic crab stages. Mar Freshw Res 54:841-845

Kingsford MJ, Leis JM, Shanks A, Lindeman KC, Morgan SG, Pineda J (2002) Sensory environments, larval abilities and local self-recruitment. Bull Mar Sci 70:309-340

- Lecchini D, Planes S, Galzin R (2005a) Experimental assays of sensory modalities of coral reef fishes in recognition of their settlement habitat. Behav Ecol Sociobiol 58:18-26

Lecchini D, Shima J, Banaigs B, Galzin R (2005b) Larval sensory abilities and mechanisms of habitat selection of a coral reef fish during settlement. Oecologia 143:326-334 Leis JM (1991) The pelagic stage of reef fishes: the larval biology of coral reef fishes. In: Sale PF (ed) The ecology of fishes and coral reefs. Academic Press, San Diego, CA, p 183-230

Leis JM (2006) Are larvae of demersal fishes nekton or plankton? Adv Mar Biol 51:57-141

Leis JM, Carson-Ewart BM (2003) Orientation of pelagic larvae of coral reef fishes in the ocean. Mar Ecol Prog Ser 252:239-253

Leis JM, Lockett MM (2005) Localization of reef sounds by settlement stage larvae of coral-reef fishes. Bull Mar Sci 76:715-724

Mann DA (2006) Propagation of fish sounds. In: Ladich F, Collin SP, Moller P, Kapoor BG (eds) Communication in fishes. Science Publishers, Enfield, NH, p 107-120

Mann DA, Casper BM, Boyle KS, Tricas TC (2007) On the attraction of larval fishes to reef sound. Mar Ecol Prog Ser 338:307-310

Montgomery JC, Jeffs A, Simpson SD, Meekan M, Tindle C (2006) Sound as an orientation cue for the pelagic larvae of reef fishes and decapod crustaceans. Adv Mar Biol 51: 143-196

Moser HG, Richards WJ, Cohen DM, Fahey MP, Kendall AW, Richardson SL (1984) Ontogeny and systematics of fishes. Am Soc Ich Herp Spec Publ 1

Myrberg AA, Fuiman LA (2002) The sensory world of coral reef fishes. In: Sale PF (ed) Coral reefs fishes: new insights into their ecology, Academic Press, San Diego, CA, p 123-148

Popper AN, Fay RR (2011) Rethinking sound detection by fishes. Hearing Res 273:25-36

Radford CA, Jeffs A, Montgomery JC (2007) Directional swimming behaviour by five species of crab postlarvae in response to reef sound. Bull Mar Sci 80:369-378

Radford CA, Jeffs AG, Tindle CT, Montgomery JC (2008a) Temporal patterns in ambient noise of biological origin from a shallow water temperate reef. Oecologia 156: 921-929

Radford CA, Jeffs AG, Tindle CT, Montgomery JC (2008b) Resonating sea urchin skeletons create coastal choruses. Mar Ecol Prog Ser 362:37-43

> Radford CA, Stanley JA, Tindle CT, Montgomery JC, Jeffs AG (2010) Localised coastal habitats have distinct underwater sound signatures. Mar Ecol Prog Ser 401:21-29

Radford CA, Stanley JA, Simpson SD, Jeffs AG (2011) Juvenile coral reef fish use sound to locate habitats. Coral Reefs 30:295-305

Rogers PH, Cox M (1988) Underwater sound as a biological stimulus. In: Atema J, Fay RR, Popper AN, Tavolga WN (eds) Sensory biology of aquatic animals. Springer, New York, NY, p 131-150

Shanks A (1995) Orientated swimming by megalopae of several eastern North Pacific crab species and its potential role in their onshore migration. J Exp Mar Biol Ecol 186: $1-16$

Simpson SD, Meekan MG, Montgomery JC, McCauley RD, Jeffs A (2004) Attraction of settlement-stage coral reef fishes to reef noise. Mar Ecol Prog Ser 276:263-268

> Simpson SD, Meekan MG, Montgomery JC, McCauley RD, Jeffs A (2005) Homeward sound. Science 308:221

Simpson SD, Jeffs AG, Montgomery JC, McCauley RD, Meekan MG (2007) Nocturnal relocation of adult and juvenile coral reef fishes in response to reef noise. Coral Reefs 27:97-104 
Simpson SD, Meekan MG, Jeffs A, Montgomery JC, McCauley RD (2008) Settlement-stage coral reef fish prefer the higher frequency invertebrate-generate audible component of reef noise. Anim Behav 75:1861-1868

Simpson SD, Radford AN, Tickle EJ, Meekan MG, Jeffs AG (2011) Adaptive avoidance of reef noise. PLoS ONE 6: e16625

Stanley J, Radford C, Jeffs AG (2010) Induction of settlement in crab megalopae by ambient underwater reef sound. Behav Ecol 21:113-120

Stobutzki IC (1998) Interspecific variation in sustained swimming ability of late pelagic stage of reef fish from two families (Pomacentridae and Chaetodontidae). Coral Reefs 17:103-110

Stobutzki IC, Bellwood DR (1997) Sustained swimming abilities of the late pelagic stages of coral reef fish. Mar Ecol Prog Ser 149:35-41
Tolimieri N, Jeffs A, Montgomery JC (2000) Ambient sound as a cue for navigation by the pelagic larvae of reef fishes. Mar Ecol Prog Ser 207:219-224

Tolimieri N, Haine O, Jeffs A, McCauley R, Montgomery JC (2004) Directional orientation of pomacentrid larvae to ambient reef sounds. Coral Reefs 23:184-191

> Wright KJ, Higgs DM, Belanger AJ, Leis JM (2008) Auditory and olfactory abilities of larvae of the Indo-Pacific coral trout, Plectropomas leopardus. J Fish Biol 72: $2543-2556$

Wright KJ, Higgs DM, Leis JM (2010) Auditory sensitivity in settlement stage larvae of coral reef fishes. Coral Reefs 29:235-243

Wysocki LE, Codarin A, Ladich F, Picciulin M (2009) Sound pressure and particle acceleration audiograms for three marine species from the Adriatic Sea. J Acoust Soc Am 126:2100-2107

Appendix 1. Derivation of reef model for sound level vs distance for an extended reef

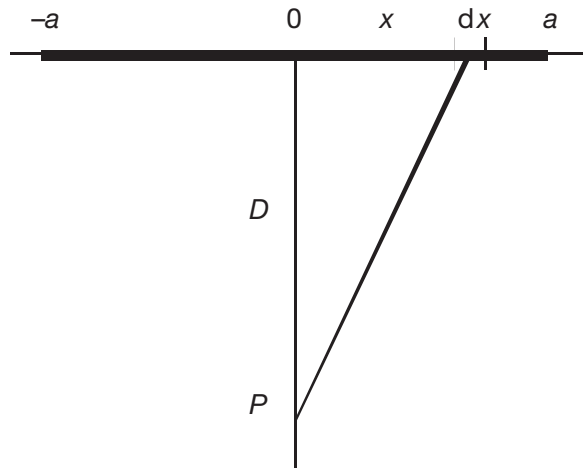

Fig. A1. Derivation of intensity vs distance

We assume the water is of uniform depth $H$ and the reef is a vertical wall occupying the full water depth. We assume the reef is covered with uniformly distributed sound sources with total output power $Q$. The power $q$ per unit length of reef is given by $q=Q /(2 a)$. The point $P$ is distance $D$ from the centre of the wall (Fig. A1). The element of length $d x$ is a vertical line source which will radiate with cylindrical spreading into water of uniform depth. The intensity $\mathrm{d} I$ at $P$ due to element $\mathrm{d} x$ is power divided by area and is given by

$$
\mathrm{d} I=\frac{q \mathrm{~d} x}{\pi H \sqrt{D^{2}+x^{2}}}
$$

The total intensity $I$ is found by integrating to give

$$
I=(2 q / \pi H) \int_{0}^{a} \frac{\mathrm{d} x}{\sqrt{D^{2}+x^{2}}}
$$

Putting $y=x / D$ and $q=Q /(2 a)$ leads to

$$
I=(Q / \pi a H) \int_{0}^{a / D} \frac{\mathrm{d} y}{\sqrt{1+\mathrm{y}^{2}}}
$$

This is a standard integral which gives

$$
I=(Q / \pi a H) \ln \left[a / D+\left(1+a^{2} / D^{2}\right)^{1 / 2}\right]
$$

There is a useful approximation for the ln function which can be written

$$
\ln \left[z+\left(1+z^{2}\right)^{1 / 2}\right] \quad \approx z \quad \text { for } z<1 / 2
$$

Therefore

$$
I \approx(Q / \pi a H)(a / D)=Q / \pi D H \text { for } D>2 a .
$$

